\title{
THE PREDICTIVE ACCCURACY FOR MORTALITY OF PERIPHERAL HEMATOLOGICAL MARKERS RATIOS IN MECHANICALLY VENTILATED COVID-19 PATIENTS
}

\section{Raja Moh'd Rashid ALKHASAWNEH ${ }^{1}$, Kais Yazid Asad GHANMA ${ }^{2}$, Shadi Odeh ALDAOUD ${ }^{3}$, Laith Siam Azzar TOEIMEH ${ }^{4}$, Ghaith Mshari ABU ALSAMEN ${ }^{1}$, Mohammed Ali OBEIDAT ${ }^{\circledR} \bowtie$, Mohammad Ahmad SHABANEH ${ }^{6}$}

${ }^{1}$ Internal Medicine/Pulmonology Department, Queen Alia Military Hospital of the Jordanian Royal Medical Services, Amman, Jordan

${ }^{2}$ Internal Medicine/Nephrology Department, Queen Alia Military Hospital of the Jordanian Royal Medical Services, Amman, Jordan

${ }^{3}$ Internal Medicine/Rheumatology Department, Queen Alia Military Hospital of the Jordanian Royal Medical Services, Amman, Jordan

${ }^{4}$ Internal Medicine/Gastroenterology Department, Queen Alia Military Hospital of the Jordanian Royal Medical Services, Amman, Jordan

${ }^{5}$ Internal Medicine/Infectious Department, Queen Alia Military Hospital of the Jordanian Royal Medical Services, Amman, Jordan

${ }^{6}$ Internal Medicine/Critical Care Department, Queen Alia Military Hospital of the Jordanian Royal Medical Services, Amman, Jordan

Received 28 Aug 2021, Accepted 04 Oct 2021

https://doi.org/10.31688/ABMU.2021.56.4.10

\section{Abstract}

Background. Hematologic markers ratios have been proposed as indicators to assist in the diagnosis and risk stratification of infectious diseases.

The objective of the study was to explore the predictive value of neutrophils and monocytes to lymphocytes ratios (NLR and MLR, respectively) and to determine their cut-off values for the early severity stratification in mechanically ventilated critically ill SARS-CoV-2 infected patients.

\section{Résumé}

Lexactitude prédictive de mortalité des taux de marqueurs hématologiques périphériques chez les patients avec COVID-19 ventilés mécaniquement

Introduction. Des taux de marqueurs hématologiques ont été proposés comme indicateurs pour aider au diagnostic et à la stratification du risque de maladies infectieuses.

L'objectif de l'étude était d'explorer la valeur prédictive des rapports neutrophiles et monocytes aux 
Material and methods. This study was retrospectively conducted on 193 patients admitted with COVID-19 in a specialized center in Jordan. Data were retrieved from the electronic medical record system over 9 months, between April - December 2020. Patients aged below 18 years, with a hospital length of stay less than 7 days, and whose studied variables were totally or partially missed were excluded from our study. An Independent and One-Sample T-Tests were used for parametric comparative data while non-parametric comparative variables were analysed using Chi Square Test. A receiver operating characteristic (ROC) was plotted to investigate the area under each curve (AUROC) of the tested prognosticator.

Results. The mean age of the entire study group was $58.37 \pm 9.96$ years, and the survivor group was insignificantly older than the non-survivor group $(58.55 \pm 9.95$ years versus $58.09 \pm 10.05$ years, respectively). The 28-day intensive care unit mortality was detected in 94 patients $(48.70 \%)$ during a mean of $12.40 \pm 4.79$ days. NLR and MLR were significantly lower in the survivor group compared to the non-survivor cohort $(2.22 \pm 0.99$ and $0.25 \pm 0.10$ versus $5.16 \pm 2.08$ and $0.89 \pm 0.19$, respectively, $\mathrm{p}<0.05$ ).

Conclusions. In this study, the higher values of MLR and NLR in patients with COVID-19, particularly in those with mechanical ventilation, could be used as predictors for risk stratification of patients with COVID-19.

Keywords: neutrophils to lymphocyte ratio, monocyte to lymphocyte ratio, COVID-19, mechanically ventilated.

\section{List of abbreviations:}

COVID-19 = coronavirus disease 2019.

$\mathrm{ROC}=$ receiver operating characteristic

AUROC $=$ area under the ROC curve

ICU $=$ intensive care unit

MLR = monocytes to lymphocytes ratio

NLR = neutrophils to lymphocytes ratio

SARS-CoV-2 = severe acute respiratory syndrome coronavirus 2

ARDS $=$ acute respiratory distress syndrome

\section{INTRODUCTION}

Coronavirus disease 2019 (COVID-19), caused by the severe acute respiratory syndrome coronavirus 2 (SARS-CoV-2), has spread rapidly throughout the world ${ }^{1-3}$. SARS-CoV-2 has a unique pathogenicity and reputation of a deadly virus. Fever is often the primary symptom of COVID-19 and can be accompanied by another symptoms $s^{4.5}$. The entire world has lymphocytes (NLR et MLR, respectivement) et de déterminer leurs valeurs seuil pour la stratification de la gravité précoce chez les patients infectés par le SRAS-CoV-2 gravement malades et ventilés mécaniquement.

Matériel et méthodes. Cette étude a été menée rétrospectivement sur 193 patients admis avec COVID-19 dans un centre spécialisé en Jordanie. Les données ont été extraites du système de dossier médical électronique sur 9 mois, entre avril et décembre 2020. Les patients âgés de moins de 18 ans, avec une durée d'hospitalisation inférieure à 7 jours, et dont les variables étudiées ont été totalement ou partiellement omises ont été exclus de notre étude. Des tests T indépendants et à un échantillon ont été utilisés pour les données comparatives paramétriques, tandis que les variables comparatives non paramétriques ont été analysées à l'aide du test du chi carré. Une caractéristique de fonctionnement du récepteur (ROC) a été tracée pour étudier l'aire sous chaque courbe (AUROC) du pronostiqueur testé.

Résultats. L'âge moyen de l'ensemble du groupe d'étude était de 58,37 $\pm 9,96$ ans, et le groupe survivant était légèrement plus âgé que le groupe non-survivant $(58,55 \pm 9,95$ ans contre $58,09 \pm 10,05$ ans, respectivement). La mortalité à 28 jours en unité de soins intensifs a été détectée chez 94 patients $(48,70 \%)$ pendant une période moyenne de $12,40 \pm 4,79$ jours. Le NLR et le MLR étaient significativement plus faibles dans le groupe des survivants par rapport à la cohorte des non-survivants $(2,22 \pm 0,99$ et $0,25 \pm 0,10$ contre $5,16 \pm 2,08$ et $0,89 \pm 0,19$, respectivement, $\mathrm{p}<0,05$ ).

Conclusions. Dans cette étude, les valeurs plus élevées de MLR et NLR chez les patients atteints de COVID-19, en particulier chez ceux sous ventilation mécanique, pourraient être utilisées comme prédicteurs de la stratification du risque des patients atteints de COVID-19.

Mots-clés: rapport neutrophiles/lymphocytes, rapport monocytes/lymphocytes, COVID-19, ventilé mécaniquement.

been racing to find a new drug or use already existing drugs to treat and manage complications associated with COVID-19 until the vaccines that were recently proven effective against SARS-CoV-2 ${ }^{6-7}$.

The variable incubation period of 2 to 14 days, highly prevalent propensity, ability to update itself, and involvement not only of the respiratory tract are defining features of SARS-CoV-2 ${ }^{8-10}$. Some patients experience shortness of breath associated with 
hypoxia ${ }^{11}$ and the high-risk patients may rapidly progress to more severe stages which often include cardiovascular complications ${ }^{12-15}$.

There are several theories explaining COVID-19". related mortality, particularly in the critically ill mechanically ventilated group, including, but not limited to, hyperinflammation-associated cytokine storm, hyperoxia-associated radical storms, and hypercoagulation associated thrombotic storm ${ }^{16}$. To date, a storm of hyperinflammatory cytokines is the most plausible theory ${ }^{17}$.

Corticosteroids are often used to manage the severe consequences of excessive inflammation, such as severe acute respiratory distress, which accompanies excessive cytokine secretion in viral infections, due to their anti-inflammatory effect ${ }^{18}$. Almost all health care sectors focus on treating symptoms and reducing the mortality associated with COVID-19 ${ }^{19}$.

Hematological markers ratios, including neutrophils to lymphocytes ratio (NLR), monocytes to lymphocytes ratio (MLR), and platelets to lymphocytes ratio (PLR), have been proposed as indicators to aid in the early stratification of infectious diseases. The inflammatory response can stimulate neutrophil production and accelerate lymphocyte apoptosis, but when corticosteroids are used the number of intravascular neutrophils increases in contrast to the numbers of monocytes and lymphocytes, which decrease ${ }^{20}$.

Because MLR takes into account both monocyte and lymphocyte counts, it has been proposed as a novel biomarker for diagnosing and predicting systemic inflammatory response syndromes ${ }^{21}$. A higher MLR results from either an increased monocyte count, a decreased lymphocyte count, or both. The NLR has been demonstrated to be an informative marker for the diagnosis and severity of disease in community-acquired pneumonia and bacteremia. MLR and PLR have also been recognized as alternative markers for the diagnosis of influenza virus infection in patients with respiratory symptoms ${ }^{22}$. A higher MLR value indicates higher odds of bacterial infection and lower odds of viral infection. Similarly, a higher NLR value indicates higher odds of bacterial infection and lower odds of viral infection ${ }^{23}$. Corticosteroids raise the number of neutrophils in the plasma and at the same time reduce the number of monocytes and lymphocytes. Therefore, intensive cortico-therapy used in COVID-19 patients with acute respiratory distress syndrome (ARDS), especially those mechanically ventilated, may overestimate the predictive values of NLR in contrast to MLR ${ }^{24}$.

The "hyper-oxidative radical storm" suggests that the pathogenesis of COVID-19 may be in part caused by excessive iron, that is a strong oxidant ${ }^{25}$. In SARS-CoV-2 infection, both neutrophil and monocyte counts are elevated, contrary to other viral infections that present monocytes' downregulation ${ }^{26}$. Most patients with SARS-CoV-2 infection present lymphocytopenia and monocytosis, which is misleading to over-prescription of unnecessary antibiotics because of the unique pathogenesis of SARS-Co-V2 infection associated with elevated MLR ${ }^{27}$.

There is a need to monitor the evolution of COVID-19 with specific, affordable, feasible, viable and cost-effective serum tests.

The OBJECtive OF THE STUDY was to investigate the predictive performance of MLR versus NLR in critically ill COVID-19 patients under treatment with corticosteroids.

\section{Materials AND MEthods}

A retrospective study was conducted in all patients with COVID-19 undergoing mechanical ventilation in a specialized COVID-19 isolation center at Queen Alia Military Hospital of the Royal Medical Services in Jordan, between April - December 2020. The criteria for exclusion were the age $<18$ years, patients with hospital length of stay (LOS) less than 7 days, and those with studied variables totally or partially missed.

This study was approved by the Jordanian Royal Medical Services ethical review board (IRB) [Ref\# 1/2021_37].

193 eligible studied patients' data were retrospectively retrieved from our electronic medical record system (Hakeem). The analytical variants were first evaluated for a normal distribution using the Kolmogorov-Smirnov test. Normally distributed continuous variables were expressed as mean $\pm \mathrm{SD}$ using the independent $\mathrm{T}$ test while non-standard categori$\mathrm{cal} /$ ordinal variables were expressed as number (percentages) by Chi Square test or mean (IQR) using Mann test -Whitney U Test, straight. Comparative variables were compared across group 1 (survivors) and group 2 (non-survivors). A receiver operating characteristic curve (ROC) followed by a sensitivity analysis was used to determine the area under the ROC curves (AUROCs) and predictive performance. Statistical analysis was performed using IBM SPSS Edition. 25 (IBM Corp., Armonk, NY, USA) and p-values $\leq 0.05$ values were considered statistically significant.

\section{Results}

Of the 374 COVID-19 patients, 193 patients were finally included in this study. The others were excluded because of either they did not develop ARDS or they had incompletely registered baseline 
Table 1. Mechanically ventilated critically ill COVID-19 patients' clinical variables and outcome data between subgroup 1 (survivors) and subgroup 2 (non-survivors).

\begin{tabular}{|c|c|c|c|c|c|}
\hline \multicolumn{2}{|l|}{ Variables } & $\begin{array}{c}\text { Total } \\
(N=193)\end{array}$ & $\begin{array}{c}\text { Survivors } \\
(N=99)\end{array}$ & $\begin{array}{c}\text { Non-Survivors } \\
(N=94)\end{array}$ & P-value \\
\hline \multicolumn{2}{|c|}{ Mean age (Yrs) } & $58.37 \pm 9.96$ & $58.55 \pm 9.948$ & $58.09 \pm 10.053$ & $0.92(\mathrm{NS})$ \\
\hline \multirow{2}{*}{ Gender } & Male & $127(65.8 \%)$ & $67(67.68 \%)$ & $60(63.83 \%)$ & \multirow{2}{*}{$0.02(\mathrm{~S})$} \\
\hline & Female & $66(34.2 \%)$ & $32(32.32 \%)$ & $34(36.17 \%)$ & \\
\hline \multicolumn{2}{|c|}{ Pre-ICU admission days } & $4.27 \pm 3.91$ & $2.23 \pm 1.06$ & $7.42 \pm 4.57$ & $0.00\left(\mathrm{~S}^{*}\right)$ \\
\hline \multicolumn{2}{|c|}{ ICU Stay day $(\mathrm{s})$} & $12.40 \pm 4.79$ & $9.23 \pm 1.06$ & $17.30 \pm 4.14$ & $0.00\left(\mathrm{~S}^{*}\right)$ \\
\hline \multicolumn{2}{|c|}{ Hospital Stay day(s) } & $16.67 \pm 6.81$ & $11.46 \pm 2.12$ & $24.72 \pm 1.98$ & $0.00\left(\mathrm{~S}^{*}\right)$ \\
\hline \multirow{2}{*}{ Number of comorbidities } & $0,1,2$ & $74(\%)$ & $52(52.53 \%)$ & $37(39.36 \%)$ & \multirow{2}{*}{$0.08(\mathrm{NS})$} \\
\hline & $3,4,5$ & $89(\%)$ & $47(47.47 \%)$ & $57(60.64 \%)$ & \\
\hline \multicolumn{2}{|l|}{$\mathrm{BW}(\mathrm{Kg})$} & $74.17 \pm 10.24$ & $74.63 \pm 10.06$ & $73.45 \pm 10.56$ & $0.61(\mathrm{NS})$ \\
\hline \multicolumn{2}{|c|}{$\mathrm{BMI}\left(\mathrm{Kg} / \mathrm{m}^{2}\right)$} & $25.92 \pm 4.00$ & $26.19 \pm 3.85$ & $25.50 \pm 4.22$ & $0.31(\mathrm{NS})$ \\
\hline \multicolumn{2}{|c|}{ 28-day ICU Survival } & \multicolumn{4}{|c|}{$99(51.29 \%)$} \\
\hline \multirow{3}{*}{ 28-day ICU Mortality } & Overall & \multicolumn{4}{|c|}{$94(48.70 \%)$} \\
\hline & Early Phase & \multicolumn{4}{|c|}{$31(16.06 \%)$} \\
\hline & Late Phase & \multicolumn{4}{|c|}{$63(32.64 \%)$} \\
\hline
\end{tabular}

Legend: Yrs: Years; Kg: Kilogram; m: Meter; BW: Actual body weight at admission; BMI: Body mass index at admission; ICU: Intensive care unit; S: Significant (p-value <0.05); NS: Non-significant (p-Value >0.05); N: Number of critically ill patients.

Table 2. Mechanically ventilated critically ill COVID-19 patients' paraclinical variables and outcome data between subgroup 1 (survivors) and subgroup 2 (non-survivors).

\begin{tabular}{|c|c|c|c|c|}
\hline Variables & $\begin{array}{c}\text { Total } \\
(N=193)\end{array}$ & $\begin{array}{l}\text { Subgroup } 1 \\
\text { Survivors } \\
(N=99)\end{array}$ & $\begin{array}{c}\text { Subgroup } 1 \\
\text { Non-survivors } \\
(N=94)\end{array}$ & P-value \\
\hline NE Rate $(\mathrm{mcg} / \mathrm{min})$ & $9.53 \pm 1.79$ & $9.27 \pm 1.68$ & $9.94 \pm 1.89$ & $0.72(\mathrm{NS})$ \\
\hline $\operatorname{GCS}(3-15)$ & $12(12-13)$ & $12(12-13)$ & $12(12-13)$ & $0.34(\mathrm{NS})$ \\
\hline Child-Pugh Score (5-15) & $6(6-8)$ & $6(6-8)$ & $6(6-7)$ & $0.09(\mathrm{NS})$ \\
\hline H.ALB (g/day) & $16.99 \pm 5.11$ & $18.89 \pm 3.16$ & $14.06 \pm 6.09$ & $0.00\left(\mathrm{~S}^{*}\right)$ \\
\hline $\operatorname{ALB}(\mathrm{g} / \mathrm{dL})$ & $2.61 \pm 0.13$ & $2.64 \pm 0.12$ & $2.57 \pm 0.13$ & 0.44 (NS) \\
\hline $\mathrm{CRP}(\mathrm{mg} / \mathrm{dL})$ & $34.16 \pm 17.93$ & $88.38 \pm 34.38$ & $143.09 \pm 59.28$ & $0.01\left(\mathrm{~S}^{*}\right)$ \\
\hline CRP: ALB & $45.44 \pm 21.61$ & $31.92 \pm 19.06$ & $58.71 \pm 24.91$ & $0.00\left(\mathrm{~S}^{*}\right)$ \\
\hline $\operatorname{FER}(\mathrm{ng} / \mathrm{mL})$ & $676.67 \pm 187.77$ & $465.76 \pm 154.07$ & $891.51 \pm 377.82$ & $0.00\left(\mathrm{~S}^{*}\right)$ \\
\hline FER: ALB & $262.76 \pm 91.35$ & $176.33 \pm 76.62$ & $346.11 \pm 112.85$ & $0.00\left(\mathrm{~S}^{*}\right)$ \\
\hline $\mathrm{SI}(\mathrm{bpm} / \mathrm{mmHg})$ & $1.19 \pm 0.14$ & $1.12 \pm 0.03$ & $1.29 \pm 0.17$ & $0.00\left(\mathrm{~S}^{*}\right)$ \\
\hline LDH (IU/L) & $308.88 \pm 44.90$ & $234.55 \pm 34.22$ & $383.56 \pm 54.11$ & $0.00\left(\mathrm{~S}^{*}\right)$ \\
\hline D-Dimer (mg/L) & $0.69 \pm 0.35$ & $0.58 \pm 0.21$ & $0.79 \pm 0.41$ & $0.00\left(\mathrm{~S}^{*}\right)$ \\
\hline WBCs (Cells/ $/ \mathrm{l})$ & $17550 \pm 2187$ & $15201 \pm 2710$ & $19880 \pm 2031$ & $0.00\left(\mathrm{~S}^{*}\right)$ \\
\hline$\%$ Neutrophils & $68.51 \% \pm 14.22 \%$ & $63.36 \% \pm 10.19 \%$ & $74.20 \% \pm 28.33 \%$ & $0.00\left(\mathrm{~S}^{*}\right)$ \\
\hline Neutrophils Count (Cells/ $\mu \mathrm{L})$ & $12178 \pm 1866$ & $9644 \pm 1995$ & $14522 \pm 2487$ & $0.00\left(\mathrm{~S}^{*}\right)$ \\
\hline \%Lymphocytes & $21.74 \% \pm 7.41 \%$ & $29.66 \% \pm 9.89 \%$ & $14.24 \% \pm 3.09 \%$ & $0.00\left(\mathrm{~S}^{*}\right)$ \\
\hline 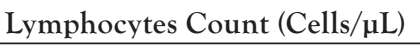 & $3645 \pm 311$ & $4410 \pm 422$ & $2866 \pm 210$ & $0.00\left(\mathrm{~S}^{*}\right)$ \\
\hline \%Monocytes & $8.90 \% \pm 2.60 \%$ & $7.45 \% \pm 1.73 \%$ & $12.85 \% \pm 2.98 \%$ & $0.00\left(\mathrm{~S}^{*}\right)$ \\
\hline Monocytes Count (Cells/ $/ \mathrm{L})$ & $1832 \pm 255$ & $1108 \pm 112$ & $2550 \pm 421$ & $0.00\left(\mathrm{~S}^{*}\right)$ \\
\hline NLR & $3.71 \pm 2.21$ & $2.22 \pm 0.99$ & $5.16 \pm 2.08$ & $0.00\left(\mathrm{~S}^{*}\right)$ \\
\hline MLR & $0.59 \pm 0.16$ & $0.25 \pm 0.10$ & $0.89 \pm 0.19$ & $0.00\left(\mathrm{~S}^{*}\right)$ \\
\hline
\end{tabular}

Legend: N: Number of critically ill patients; bpm: beat per minute; mcg: microgram; min: minute; S: Significant (p-value <0.05); NS: Non-significant (p-value >0.05); NE: Norepinephrine; NLR: Neutrophils to lymphocytes ratio; MLR: Monocytes to lymphocytes ratio. SI: Shock index; H.ALB: Human Albumin 20\%; GCS: Glasgow coma scale; ALB: Albumin level; CRP: C-reactive protein; FER: Ferritin; LDH: Lactate dehydrogenase; CRP: $A L B=C R P$ to ALB ratio; FER: ALB= FER to ALB ratio. 
Table 3. The optimal cut-off point, sensitivity, specificity, positive and negative predictive values, Youden and accuracy indices for the two tested mortality prognosticators of lymphocytes, NLR and MLR.

\begin{tabular}{ccccccccc}
\hline Prognostic Indicator & Cut-off & TPR & FPR & YI & TNR & PPV & NPV & AI \\
\hline Lymphocytes (Cells/ $\mu \mathrm{l})$ & 3116 & $71.32 \%$ & $36.81 \%$ & $34.51 \%$ & $63.19 \%$ & $65.96 \%$ & $68.78 \%$ & $67.26 \%$ \\
\hline NLR & 9.51 & $61.05 \%$ & $20.10 \%$ & $40.95 \%$ & $81.89 \%$ & $75.23 \%$ & $67.77 \%$ & $70.77 \%$ \\
\hline MLR & 0.67 & $66.79 \%$ & $23.69 \%$ & $43.10 \%$ & $76.31 \%$ & $73.82 \%$ & $69.68 \%$ & $71.55 \%$ \\
\hline
\end{tabular}

Legend: CRP: C-reactive protein; FER: Plasma ferritin level; TPR: True positive rate (sensitivity); FPR: False positive rate; PPV: Positive predictive value; NPV: Negative predictive value; YI: Youden index; AI: Accuracy index; TNR: True negative ratio (specificity); MLR: Monocytes to lymphocytes ratio; NLR: Neutrophils to lymphocytes ratio.

ROC curve analysis of the tested prognosticators for overall 28-day ICU mortality.

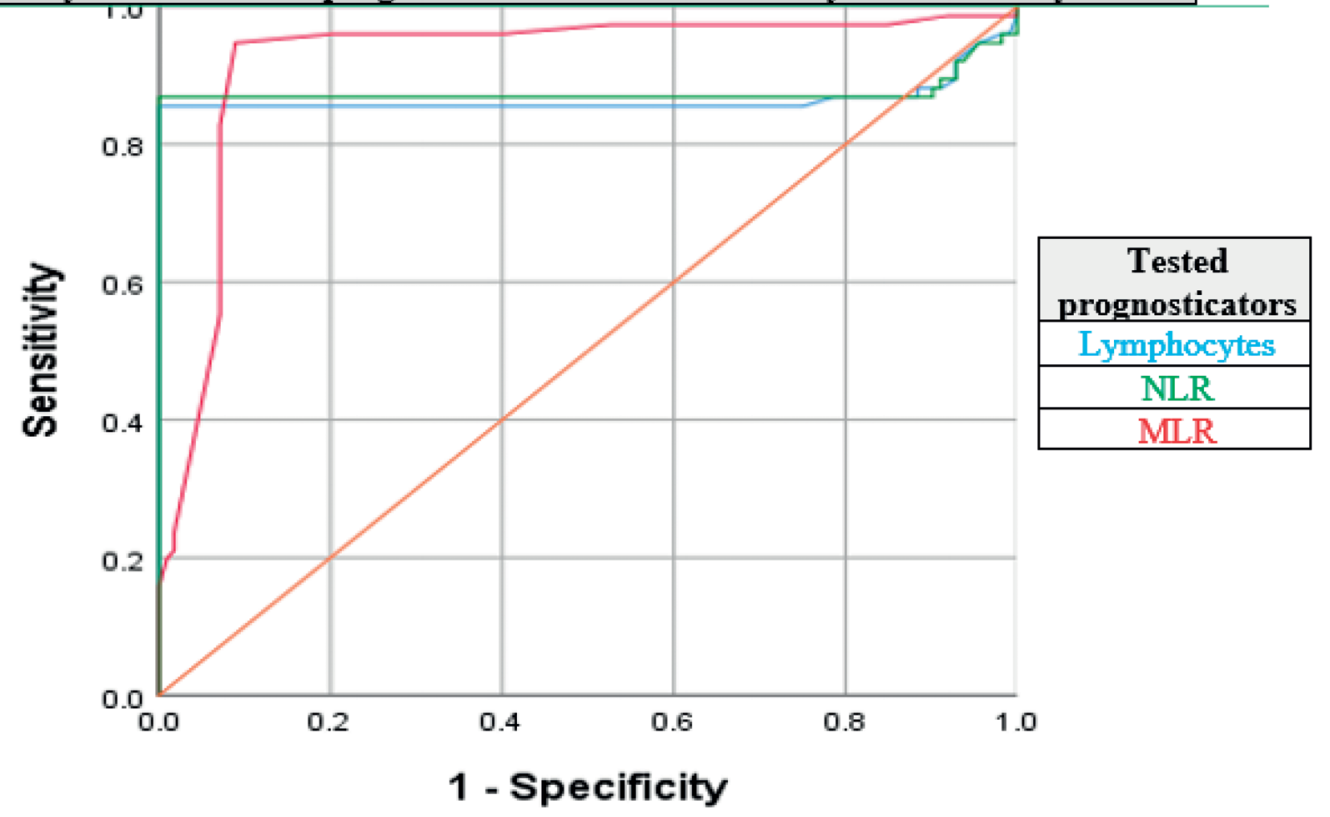

Figure 1. Receiver operating characteristics (ROC) curve analysis of the lymphocytes, neutrophils to lymphocytes ratio (NLR), and monocytes to lymphocytes ratio (MLR) to determine the area under curve (AUC) and therefore there's predictive efficacy overall 28-day mortality of the two tested prognosticators (NLR and MLR) in addition to lymphocytes. The AUROC was significantly highest in MLR (0.923; 95\% CI, 0.877-0.969) followed by NLR (0.874; 95\% CI, 0.802-0.947), and lymphocytes (0.865; 95\% CI, 0.791-0.939).

or follow-up data. 99 patients belonged to group 1 (survivors) and 94 to group 2 (non-survivors).

The mean age of the entire study group was $58.37 \pm 9.96$ years; the survivor group was insignificantly older than the non-survivor group $(58.55 \pm 9.95$ years versus $58.09 \pm 10.05$ years, respectively). The men to women ratio in the group of study was 127 to 66 (65.8\% vs 34.2\%). 67 (67.68\%) COVID-19 critically ill men and 32 (32.32\%) critically ill COVID-19 women belonged to the survivors group compared to $60(63.83 \%)$ critically ill COVID-19 men and 34 (36.17\%) critically ill women who belonged to the non-survivor group.

White blood cells, NLR, MLR, neutrophil and monocyte counts were significantly lower in the survivor group compared to the non-survivor group. NLR and MLR were also significantly lower in the survivor group compared to the non-survivor group $(2.22 \pm 0.99$ and $0.25 \pm 0.10$ versus $5.16 \pm 2.08$ and $0.89 \pm 0.19$, respectively, $\mathrm{p}<0.05$ ). In contrast, the percentage and number of lymphocytes were significantly higher in the survivor group compared to the non-survivor group.

Hemodynamically, the shock index (SI) is significantly lower in the survivor group compared to the non-survivor cohort $(1.12 \pm 0.03 \mathrm{bpm} / \mathrm{mmHg}$ versus $1.29 \pm 0.17 \mathrm{bpm} / \mathrm{mmHg}$, respectively, $\mathrm{p}<0.05$ ). C-reactive protein (CRP) and ferritin (FER), two widely used prognostic indicators belonging to the acute-phase reactants, were significantly higher in the non-survivor group than in the survivor group $(143.09 \pm 59.28 \mathrm{mg} / \mathrm{dL}$ and $891.51 \pm 377.82 \mathrm{ng} / \mathrm{mL}$ versus $88.38 \pm 34.38 \mathrm{mg} / \mathrm{dL}$ and $465.76 \pm 154.07 \mathrm{ng} / \mathrm{mL}$, respectively, $\mathrm{p}<0.05$ ). 
The primary outcome of this study (28-day ICU mortality) was detected in 94 patients $(48.70 \%)$ over a mean duration of ICU stay of $12.40 \pm 4.79$ days and overall hospital stay of $16.67 \pm 6.81$ days, as both were also significantly higher in the non-survivor group compared to the survivor cohort $(17.30 \pm 4.14$ days and $24.72 \pm 1.98$ days versus $9.23 \pm 1.06$ days and $11.46 \pm 2.12$ days, respectively, $\mathrm{p}<0.005$ ). Also, the non-survivor group was also divided into two phases, the early phase (14 days) and the late phase (>14 days); the mortality was lower in the early stage compared to the late stage [31 patients $(16.06 \%)$ versus 63 patients $(32.64 \%), \mathrm{p}<0.05]$. The comparative variables and analytical outcome data between the two groups (survivors and non-survivors) are summarized in Tables 1-2.

Table 3 shows the best cut-off values for lymphocytes, NLR, MLR in predicting the mortality, which were 3116 cells $/ \mu \mathrm{L}, 9.51$, and 0.67 , respectively. Figure 1 shows the ROC curve analysis of the lymphocytes, NLR and MLR to determine the area under curve (AUC) and therefore the predictive efficacy for overall 28-day mortality of the two tested prognosticators (NLR and MLR) in addition to lymphocytes. The AUROC was significantly higher in MLR (0.923; 95\% CI, 0.877-0.969), followed by NLR $(0.874 ; 95 \%$ CI, 0.802-0.947), and lymphocytes $(0.865 ; 95 \% \mathrm{CI}$, 0.791-0.939).

\section{Discussion}

Monocytes, neutrophils, and lymphocytes are three major components of the immune system and play versatile roles in patients with COVID-19. Our study was mainly focused on assessing severity and prognosis from the point of view of the tested hematological variables. We investigated the utility of performing monocyte, neutrophil, and lymphocyte lineage in predicting the key clinical outcomes of ICU patients with COVID-19.

Both MLR and NLR are cost-efficient and correlated to disease duration. Both are elevated in bacterial infections. For example, a study of 1468 patients concluded that the use of MLR or NLR provides a better prediction than CRP or white blood cells in estimating septicemia in critically ill patients ${ }^{28}$. Several case reports and studies have shown the efficiency of corticosteroids in reducing early-stage ARDS, decreasing the severity of lung injury, organ dysfunction, and increasing the number of days without mechanical ventilation ${ }^{29}$. However, the use of corticosteroids affected the ability to use a higher NLR, and thus the selection of the MLR is more practical in these scenarios, reducing the misleading results and unnecessary antibiotic prescribing, which justifies the reason for choosing the MLR over the NLR in COVID-19 patients.
Our study revealed an important role of NLR and MLR in indicating more severe disease outcomes, including 28-day risk of death, especially in critically ill COVID-19 patients with a longer duration of hospitalization before ICU admission. The comparison of analytical variables revealed a significantly longer duration of hospitalization before ICU admission (7.42 \pm 4.57 days vs $2.23 \pm 1.06$ days) and a higher frequency of comorbidities (57 patients (60.64\%) vs 47 patients $(47.47 \%)$ with more than two comorbidities, $\mathrm{p}<0.05)$ in the non-survivor compared to the survivor group.

In some studies on Chinese population, granulocyctosis and monocytosis were reported in most critically admitted COVID-19 patients at the expense of lymphopenia ${ }^{30}$. In our research, non survivors critically ill patients had higher MLR and NLR than survivors.

As NLR and MLR are well-established indicators of systemic inflammatory status and the therapeutic efficiency of corticosteroids is associated with their capability to suppress systemic inflammation and the cytokine storm, Laforge et al. showed that the optimal NLR cut-off value for suppressing systemic inflammation with corticosteroid treatment is 6.11. After adjusting for time-varying exposure and confounders, corticosteroid treatment was associated with a lower risk of all-cause mortality when NLR $>6.11^{30}$. In our study, the optimal cut-off values for NLR and MLR in critically ill SARS-CoV-2 infected patients were 9.51 and 0.67 , respectively.

\section{Conclusions}

There is an urgent need to find an affordable and accessible marker to predict COVID-19 evolution in critically ill patients at risk of potentially fatal complications, such as ARDS and multiorgan failure. In this study, we concluded that MLR and NLR are elevated in patients with COVID-19, especially in those mechanically ventilated. This study is limited by its retrospective design. A larger, multi-site prospective study is needed to control for multiple confounders and elucidate the causal relationship between the tested prognostic factors and mortality. Despite these limitations, our findings may be of added value to the changing and controversial evidence, particularly in critical groups.

\section{Author Contributions}

R.M.R.A. and M.A.O. equally contributed to the conception and design of the research; M.A.O. and K.Y.A.G. contributed to the design of the research; S.O.A., L.S.A.T., and M.A.O. contributed to the interpretation of the data; 
and M.A.O., G.M.A., and M.A.S. drafted the manuscript. All authors critically revised the manuscript, agree to be fully accountable for ensuring the integrity and accuracy of the work, and read and approved the final manuscript.

\section{Compliance with Ethics Requirements:}

"The authors declare no conflict of interest regarding this article"

"The authors declare that all the procedures and experiments of this study respect the ethical standards in the Helsinki Declaration of 1975, as revised in 2008(5), as well as the national law."

"No funding for this study"

\section{Acknowledgements:}

"The authors would like to express their gratitude to all medical teams who gave them the opportunity to do this project."

\section{References}

1. Almazan F, Gonzalez JM, Penzes Z, et al. Engineering the largest RNA virus genome as an infectious bacterial artificial chromosome. Proc Natl Acad Sci. USA. 2000;97:5516-5521.

2. Almazan F, Dediego ML, Galan C, et al. Construction of a severe acute respiratory syndrome coronavirus infectious cDNA clone and a replicon to study coronavirus RNA synthesis. J Virol. 2006;80:10900-10906.

3. Almeida MS, Johnson MA, Herrmann T, Geralt M, Wuthrich K. Novel beta-barrel fold in the nuclear magnetic resonance structure of the replicase nonstructural protein 1 from the severe acute respiratory syndrome coronavirus. J Virol. 2007;81:3151-3161.

4. Gorbalenya AE, Baker SC, Baric RS, et al. Severe acute respiratory syndrome-related coronavirus: the species and its viruses - a statement of the Coronavirus Study Group. BioRxiv. 2020 doi: 10.1101/2020.02.07.937862.

5. Burki TK. Coronavirus in China. Lancet Respir Med. 2020;8(3):238

6. Bassetti M, Vena A, Giacobbe DR. The novel Chinese coronavirus (2019-nCoV) infections: challenges for fighting the storm. Eur J Clin Investig. 2020;50(3):e13209.

7. Cao B, Wang Y, Wen D, et al. A trial of Lopinavir-Ritonavir in adults hospitalized with severe Covid-19. N Engl J Med. 2020;382:1787-1799.

8. Chinazzi M, Davis JT, Ajelli M, et al. The effect of travel restrictions on the spread of the 2019 novel coronavirus (COVID-19) outbreak. Science. 2020;368(6489):395-400.

9. Gao Y, Shi C, Chen Y, et al. A cluster of the corona virus disease 2019 caused by incubation period transmission in Wuxi, China. J Infect. 2020;80(6):666-70.

10. Chun JY, Baek G, Kim Y. Transmission onset distribution of COVID-19. Int J Infect Dis. 2020;99:403-7.

11. Rodriguez-Morales AJ, Cardona-Ospina JA, Gutierrez-Ocampo E, et al. Clinical, laboratory and imaging features of COVID-19: a systematic review and meta-analysis. Travel Med Infect Dis. 2020; 34:101623.

12. Wang B, Li R, Lu Z, Huang Y. Does comorbidity increase the risk of patients with COVID-19: evidence from meta-analysis. Aging (Albany NY). 2020;12(7):6049-57.
13. Yang J, Zheng Y, Gou X, et al. Prevalence of comorbidities and its effects in patients infected with SARS-CoV-2: a systematic review and meta-analysis. Int J Infect Dis. 2020;94:915.

14. Liu K, Chen Y, Lin R, Han K. Clinical feature of COVID-19 in elderly patients: a comparison with young and middle-aged patients. J Inf Secur. 2020;80(6):e14-8.

15. Thompson BT, Chambers RC, Liu KD. Acute respiratory distress syndrome. N Engl J Med. 2017;377(6):562-572.

16. Al-Samkari H, Karp Leaf RS, Dzik WH, et al. COVID-19 and coagulation: bleeding and thrombotic manifestations of SARS-CoV-2 infection. Blood. 2020;136:489-500.

17. Lai C-C, Shih T-P, Ko W-C, Tang H-J, Hsueh P-R. Severe acute respiratory syndrome coronavirus 2 (SARS-CoV-2) and coronavirus disease-2019 (COVID-19): The epidemic and the challenges. Int J Antimicrob Agents. 2020;55(3):105924.

18. McElvaney OJ, McEvoy NL, McElvaney OF, et al. Characterization of the inflammatory response to severe COVID-19 illness. Am J Respir Crit Care Med. 2020;202(6):812-821.

19. Wan S, Yi Q, Fan S, Lv J, Zhang X, Guo L. Characteristics of lymphocyte subsets and cytokines in peripheral blood of 123 hospitalized patients with 2019 novel coronavirus pneumonia (NCP) medRxiv. 2020. https://doi.org/10.1101/2020. 02.10.20021832.

20. Qin C, Zhou L, Hu Z, et al. Dysregulation of immune response in patients with COVID-19 in Wuhan, China. Clin Infect Dis. 2020;71(15):762-768.

21. Yang A-P, Liu J, Tao W, Li H-M. The diagnostic and predictive role of NLR, d-NLR and PLR in COVID-19 patients. Int Immunopharmacol. 2020;106504.

22. Zahorec R, Hulin I, Zahorec P. Rationale use of neutrophil-to-lymphocyte ratio for early diagnosis and stratification of COVID-19. Bratisl Lek Listy. 2020;121(7):466-470.

23. Um S-J, Huh J-H, Choi IS, Lee S-K, Yoon N-B, Son C. Role of the neutrophil-lymphocyte count ratio in the differential diagnosis of pulmonary tuberculosis and bacterial community acquired pneumonia. In: C61. Immunodiagnostics for Latent Tuberculosis Infection and Tuberculosis. American Thoracic Society; 2012:A4737-A4737.

24. Ying HQ, Deng QW, He BS, et al. The prognostic value of preoperative NLR, d-NLR, PLR and LMR for predicting clinical outcome in surgical colorectal cancer patients. Med Oncol 2014;31(12):305.

25. Cheng L, Li H, Li L, et al. Ferritin in the coronavirus disease 2019 (COVID-19): a systematic review and meta-analysis. J Clin Lab Anal. 2020;34(10):e23618.

26. Cavezzi A, Troiani E, Corrao S. COVID-19: hemoglobin, iron, and hypoxia beyond inflammation. A narrative review. Clin. Pract. 2020, 10, 1271.

27. Ali MK, Kim RY, Brown AC, et al. Critical role for iron accumulation in the pathogenesis of fibrotic lung disease. J Pathol. 2020;251(1):49-62.

28. Akilli NB, Yortanl M, Mutlu H, et al. Prognostic importance of neutrophil-lymphocyte ratio in critically ill patients: short- and long-term outcomes. Am J Emerg Med. 2014;32:1476-1480.

29. Lissoni P, Rovelli F, Monzon A, Privitera C, Messina G, Porro G. Evidence of abnormally low lymphocyte-to-monocyte ratio in covid-19-induced severe acute respiratory syndrome. J Immunol Allergy. 2020;1(2):1-6.

30. Laforge M, Elbim C, Frère C, et al. Tissue damage from neutrophil-induced oxidative stress in COVID-19. Nat Rev Immunol. 2020;20:515-516. 